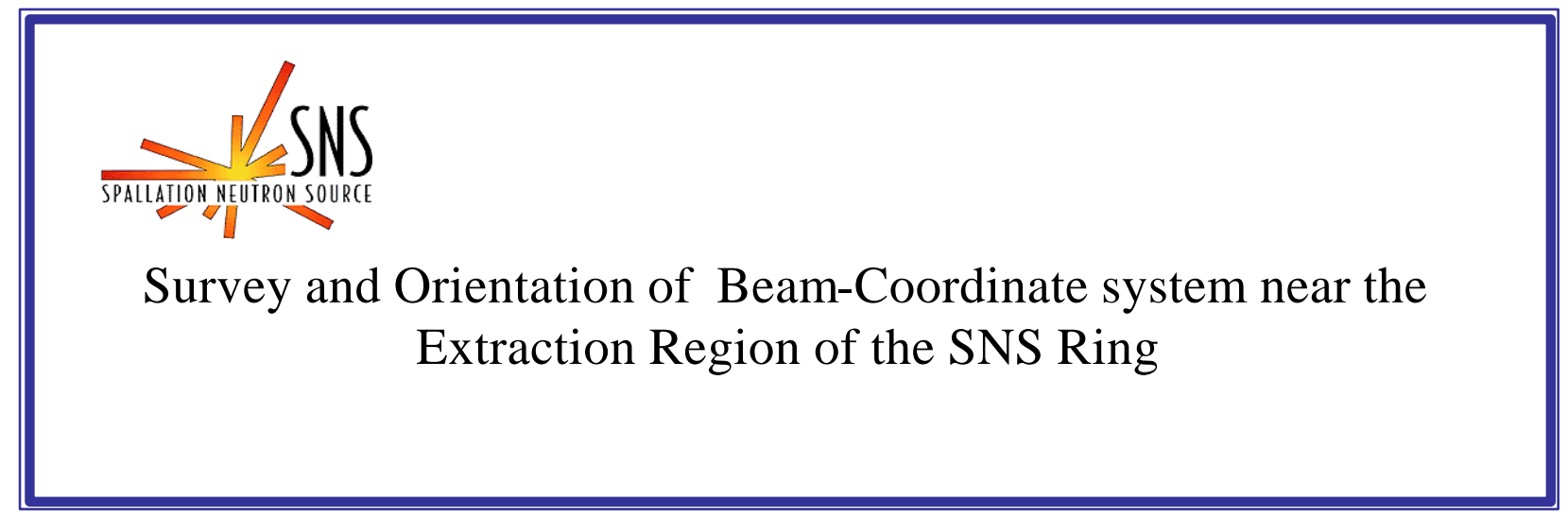

BNL/SNS TECHNICAL NOTE

NO. 094

N. Tsoupas, D. Raparia, Y.Y. Lee and J. Wei

April 25, 2001

APPROVED:

J. Wei

COLLIDER-ACCELERATOR DEPARTMENT

BROOKHAVEN NATIONAL LABORATORY

UPTON, NEW YORK 11973 


\title{
Survey and Orientation of Beam-Coordinate system near the Extraction Region of the SNS Ring
}

\section{Abstract}

\author{
N. Tsoupas, D. Raparia, Y.Y Lee, J. Wei
}

The fast beam extraction process [1] of the SNS accumulator ring [2] can be accomplished by two steps. In the first step the beam is kicked, by a set of 14 fast-kickers, vertically down to a direction making an angle $-13 \mathrm{mrad}$ with the horizontal. In the second step a septum magnet bends the beam to the left (and on the outside of the SNS accumulator ring) by $16.8^{\circ}$.

In such a magnet geometry, where the bending plane of the septum magnet is not horizontal, (The beam-bending plane makes an angle of $-13 \mathrm{mrad}$ with the horizontal) the $\mathrm{y}$-axis of the beam coordinate system, system at the exit of the septum magnet, may not coincide with the $y$-axis of the "fixed coordinate" system even when the direction of the beam (at the exit of the septum) is restored at the horizontal plane.

Such a mismatch of the y-axes of the "beam coordinate" system with the "fixed coordinate" system may cause first-order beam coupling which will be introduced by the quadrupole magnets of the beam transfer line.

In such a magnet geometry, it is common practice to roll the dipole magnets, whose bending plane is not along the horizontal, in order to bring into parallelism the y-axis of the "beam coordinate" systems with the y-axis of the "fixed" coordinate system at the exit of the dipoles. The roll of the dipole eliminates the mismatch of the y axis of the "beam coordinate" system with respect to the "fixed coordinate" system, and allows for the magnetic elements downstream of the septum to be surveyed with respect to the "fixed coordinate" system. Any linear beam-coupling which is introduced by the roll of the septum magnet can be corrected if necessary with skew quadrupole magnetic elements.

In this technical note we study the orientation of the "beam" coordinate system with respect to the "fixed" coordinate system at the exit of the septum magnet, and provide the first order transfer matrices for four separate cases:

a) No roll of the septum magnet.

b) Roll of the septum magnet for "y-axes overlap".

c) Partial roll of the septum magnet for horizontal beam direction at the exit of the septum magnet.

d) Partial roll of the septum magnet for determined beam direction at the exit of the septum magnet [3].

\section{Magnet Layout}

The layout of the magnets at the extraction region of the SNS accumulator ring can be modeled by using the following magnets:

\footnotetext{
1 In this technical note we define as "fixed coordinate" system any coordinate system whose y-axis is along the vertical ( $\mathrm{x}-\mathrm{y}$ plane is horizontal).
} 
1. A vertical dipole magnet (labeled "kicker" in Fig. 1) which "kicks" the beam by -13 mrad down from the horizontal plane. This magnet corresponds to the SNS extractionkickers.

In reality the vertical angle of $-13 \mathrm{mrad}$ is generated by a set of 14 kickers[1], which are located at different places along the ring, and therefore the phase advance of each kicker with respect to the entrance of the Lambertson septum magnet is different from the phase advance of the any other kicker.

This angle of $-13 \mathrm{mrad}$ depends on the location of the kickers as well as other constraints (magnet strength) on the extraction region and may results in a different vertical beam direction at the entrance of the Lambertson septum.

All the calculations in this technical note are based on a vertical beam direction of -13 mrad with the horizontal.

2. A DRIFT space that allows the central trajectory of the beam to reach a vertical height of $-167 \mathrm{~mm}$ (with respect to the ring plane) at the entrance of the septum magnet.

3. The septum dipole magnet (labeled "septum" in Fig 1) which bends the beam by $16.8^{\circ}$ to the left and to the outside of the SNS accumulator ring.

4. A DRIFT space.

5. A vertical dipole magnet (labeled VD2 in Fig. 1) which restores the beam direction along the horizontal plane.

APENDIX I provides a MAD-input file which describes both, the magnetic elements which model the SNS extraction region, mentioned above, as well as the layout of these magnetic elements which are shown in figure 1.

In this, MAD-input-file model, we spliced the septum magnet in the middle in order to obtain information on the coordinates of the central orbit at the center of the magnet.

The next section discusses the four different geometrical arrangements of the extraction magnetic elements $\{(\mathrm{a})$ to (d) mentioned in the Abstract section\}, and their effect on the beam coordinate system.

\section{Survey of the SNS Ring Extraction Region}

The results of this survey study which corresponds to the four different geometrical arrangements of the extraction magnetic elements, appear in APPENDIX II and are summarized in the TABLE inserted in figure 1

\section{No Roll of the septum magnet}

The "set-up" of the MAD input file and the survey results of this magnet arrangement appear in APENDIX I and II respectively under the title "NO ROLL OF THE SEPTUM MAGNET". In this magnet arrangement the roll-angle of the septum magnet is zero (TILT $=\pi / 2$ bends the beam to the left) and the beam exits the septum magnet with a slope "phi" $(\phi)$ of $-12.45 \mathrm{mrad}$ and an angle "theta" $(\theta)$ of $\sim 12.8^{\circ}(0.2932 \mathrm{mrad})$ (see APPENDIX II or insert Table in Fig. 1) . The beam exits the septum magnet at $y=-0.1983 \mathrm{~m}$ from the horizontal plane which passes through the central beam orbit of the ring. 
The $y$-axis of the "beam coordinate" system makes an angle "psi" $(\psi)$ of $3.76 \mathrm{mrad}$ (see last column of table in APPENDIX II) with respect to the vertical. This "mismatch" of the y-axis directions will introduce linear beam coupling when the beam enters a normal quadrupole. This coupling can be avoided by rolling the quadrupoles downstream of the septum magnet. The beam rotation at the target however cannot be avoided.

An alternative way to avoid the linear coupling of the beam and correct for the rotation of the "beam-coordinate" system is to introduce four skew quadrupoles downstream of the septum magnet. These quadrupoles can correct both the beam coupling and beam rotation on the target.

The vertical dipole VD2 bends the beam vertically by $+12.45 \mathrm{mrad}$ and restores the beam to the horizontal ("phi"=0) direction. The center of the beam lies at a vertical height of -21.39 cm (8.42").

The first R-Matrix which follows this survey corresponds to the R-Matrix which is in reference to the beam coordinate system. Note that there in no beam coupling in this coordinate system $\left(\mathrm{R}_{13}=0, \mathrm{R}_{14}=0\right.$...etc $)$ when there is no roll of the septum magnet. The second R-Matrix which shows linear coupling is in reference to the "fixed-coordinate" system. This linear coupling can be removed by the insertion of four skew quadrupoles downstream of the septum magnet.

\section{Roll of the septum magnet for making parallel the y-axis of the "beam coordinate" system with $y$-axis of the "fixed coordinate" system.}

The "set-up" of the MAD input file and the survey results of this magnet arrangement appear in APENDIX I and II respectively under the title "ROLL OF THE SEPTUM MAGNET FOR Y-AXES OVERLAP“.

In this magnet arrangement the roll-angle of the septum magnet is $88.161 \mathrm{mrad}$, (TILT $=\pi / 2+0.08816$ in APPENDIX I) and the beam exits the septum magnet with a slope "phi" $(\phi)$ of $+13.00 \mathrm{mrad}$ and an angle "theta" $(\theta)$ of $\sim 16.8^{\circ}$ (see APPENDIX II, or insert Table in figure 1).

The roll of the septum magnet by $88.161 \mathrm{mrad}$, has brought the $\mathrm{x}$-axis of the "beam coordinate" system at the exit of the septum, in coincidance with the horizontal \{the angle "psi" $(\psi)$ is $0.0 \mathrm{mrad}$.

The vertical dipole VD2 bends the beam by -13 mrad downwards, and restores the beam direction along the horizontal $\{$ "phi" $(\phi)=0\}$ with the center of the beam at a vertical height of $-15.08 \mathrm{~cm}$ (5.94"). At the exit of the vertical dipole VD2, the y-axis of the "beam coordinate" system overlaps with the y-axis of the "fixed coordinate" system.

The two R-Matrices which follow this survey correspond to the "beam coordinate" and the "fixed-coordinate" system respectively. The R-Matrices are identical since the y-axis of the "beam coordinate" system coincides with the y-axis of the "fixed-coordinate" system.

The linear coupling shown by the R-Matrices is due to the skew quadrupole at the entrance and exit of the septum magnet. This skew quadrupole is generated from the rotation of the septum magnet.

\section{Roll of the septum magnet to eliminate the slope of the beam direction at the exit of the septum magnet.}


The "set-up" of the MAD input file and the survey results of this magnet arrangement appear in APENDIX I and II respectively under the title "PARTIAL ROLL OF THE SEPTUM MAGNET FOR ZERO SLO PE".

In this magnet arrangement the roll-angle of the septum magnet is $43.007 \mathrm{mrad}$ and the beam exits the septum magnet along the horizontal ["phi" $(\phi)$ of $0.0 \mathrm{mrad}$ ] and an angle "theta" $(\theta)$ of $12.8^{0}$. The vertical height of the beam at the exit of the septum is $-18.3 \mathrm{~cm}\left(-7.2^{\prime \prime}\right.$ ) (see APPENDIX II or insert Table in figure 1).

The slope of the beam direction [angle "phi" $(\phi)]$ at the exit of the septum magnet depends on the roll angle of the septum magnet. It is therefore feasible, by adjusting the roll angle of the septum magnet, to achieve a horizontal beam direction and a predetermined beam height at the exit of the vertical dipole VD2. This geometric arrangement is the subject of the next section.

The two R-Matrices which follow this survey correspond to the "beam coordinate" and the "fixed-coordinate" system respectively. The two R-Matrices are different because the y-axis of the "beam-coordinate" system does not coincide with the y-axis of the "fixed coordinate" system but makes an angle "psi" $(\psi)$, of $1.92 \mathrm{mrad}$ (see last column labeled "psi" in APPENDX II).

\section{Roll of the septum magnet to achieve horizontal beam direction and reach pre-determined beam height at the exit of VD2 magnet}

The "set-up" of the MAD input file and the survey results of this magnet arrangement appear in APENDIX I and II respectively under the title "PARTIAL ROLL OF THE SEPTUM MAGNET FOR PRE-DETEMINED BEAM HEIGHT“.

In this section we study the survey of the extraction region for the particular case in which the beam center line at the exit of the vertical magnet VD2 (see figure 1) is at a predetermined height of $-18.288 \mathrm{~cm}$ from the beam center line of the SNS Ring, and the beam direction is along the horizontal.

This height of $-18.288 \mathrm{~cm}$ as measured from the beam center line of the SNS Ring, is the beam center line of the RTBT transfer line and the height of the center point of the SNS target.

This partial roll of the septum magnet[3] brings the beam center line, at the exit of the septum magnet to the same height as the RTBT beam-line height, thus reducing the strength of the vertical dipole VD2 to that of a corrector magnet (0.06 mrad see APPENDIX II column with label "phi").

In this extraction arrangement, the survey results show that the "beam coordinate" system is rotated by an angle ("psi" $(\psi)=1.91 \mathrm{mrad}$ ) with respect to the "fixed coordinate" system and the R-Matrix at the exit of the extraction region (see R-matrix following the survey results in APPENDIX II) indicates that the beam has been linearly coupled. Similarly the following R-Matrix (with respect to the "fixed coordinate" system) is also coupled.

In the next section we propose two methods to remove the linear coupling introduced by the rotation of the septum magnet can be removed by introducing four skew quadrupoles following the VD2 vertical corrector magnet.

\section{Removal of the linear coupling}


The rotation of the "beam coordinate" system with respect to the "fixed coordinate" system and the linear coupling of the beam, mentioned earlier can be eliminated, if necessary, by the one of the following two methods.

a) Introduce four, low strength, skew quads downstream of the vertical dipole VD2.

b) Introduce skew quadrupoles by the rotatation the first four or five available quads of the RTBT transfer line following the vertical dipole VD2.

\section{kicker}
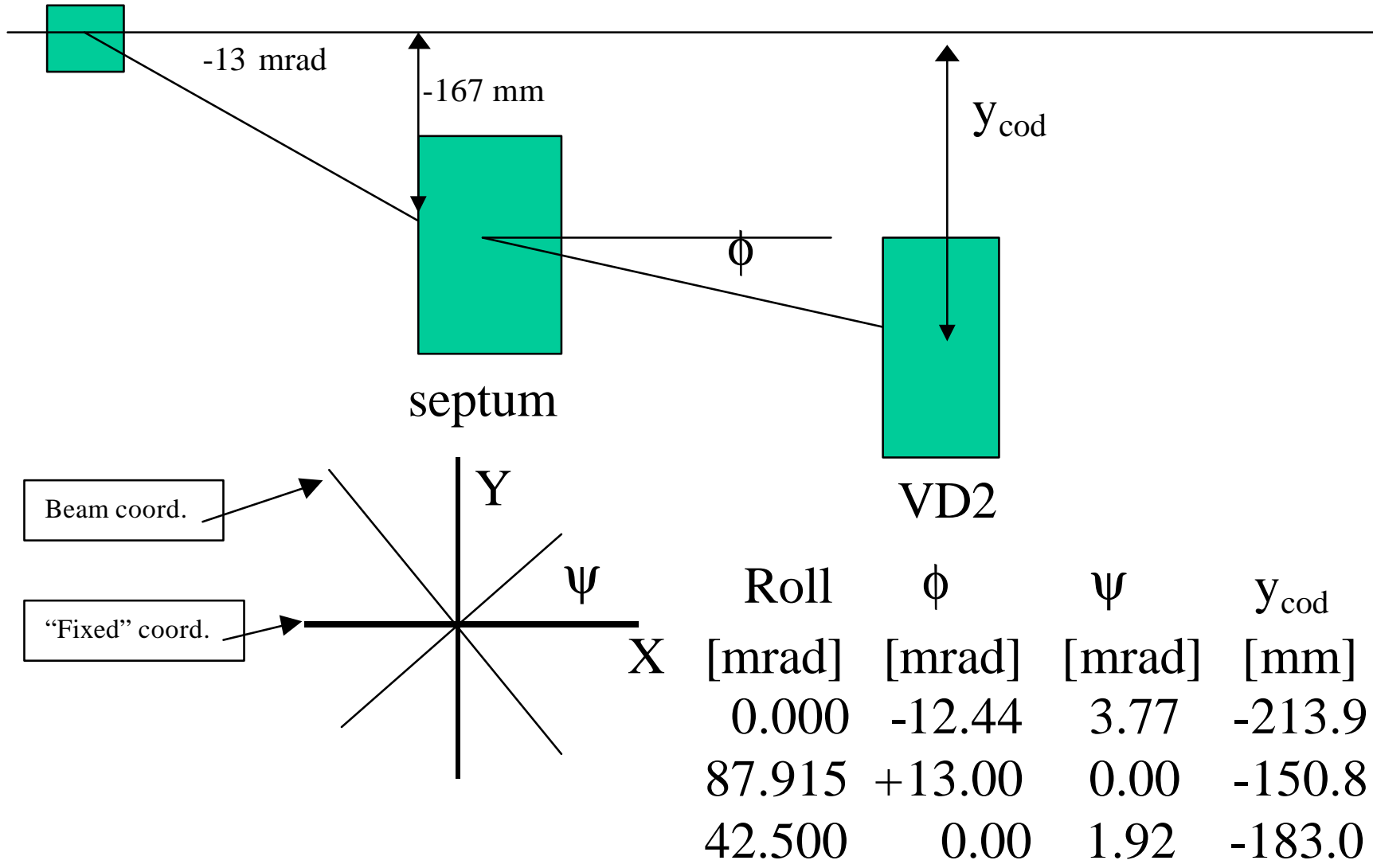

Figure 1. Schematic diagram of the layout of the magnetic elements at the SNS extraction region. 


\section{REFERANCES}

[1] N. Tsoupas et. al. "Beam Extraction from the SNS Ring and Design of Extraction Kickers" $7^{\text {th }}$ European Particle Accelerator Conference Vienna Austria June 26-30 2000

[2] J. Wei et al. "A FODO/Doublet Lattice for the SNS Accumulator Ring."

$7^{\text {th }}$ European Particle Accelerator Conference Vienna Austria June 26-30 2000

[3] Suggested by Y.Y. Lee BNL Private communication 


\section{APENDIX I}

TITLE, " SNS EXTRACTION REGION AT THE SEPTUM MAGNET"

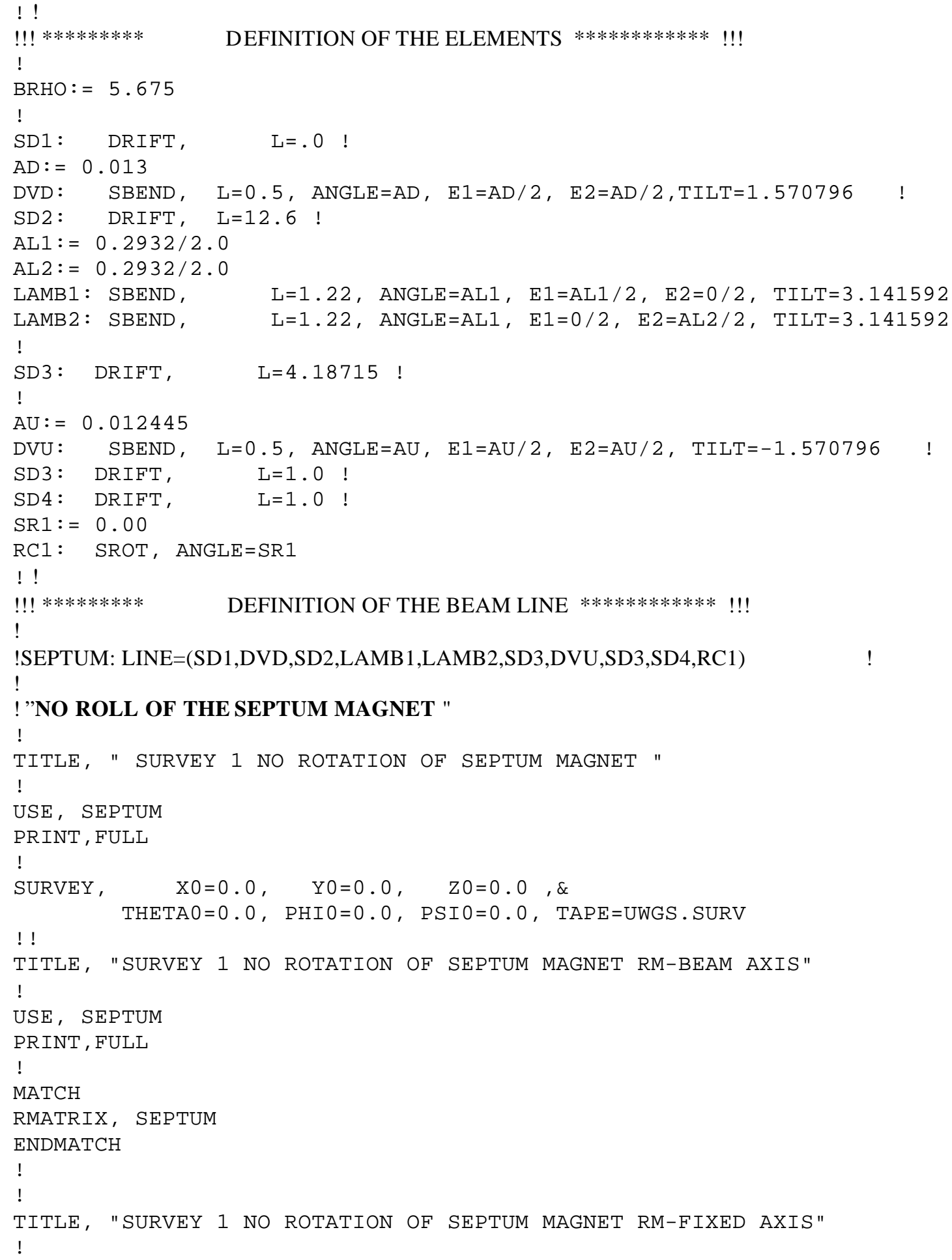




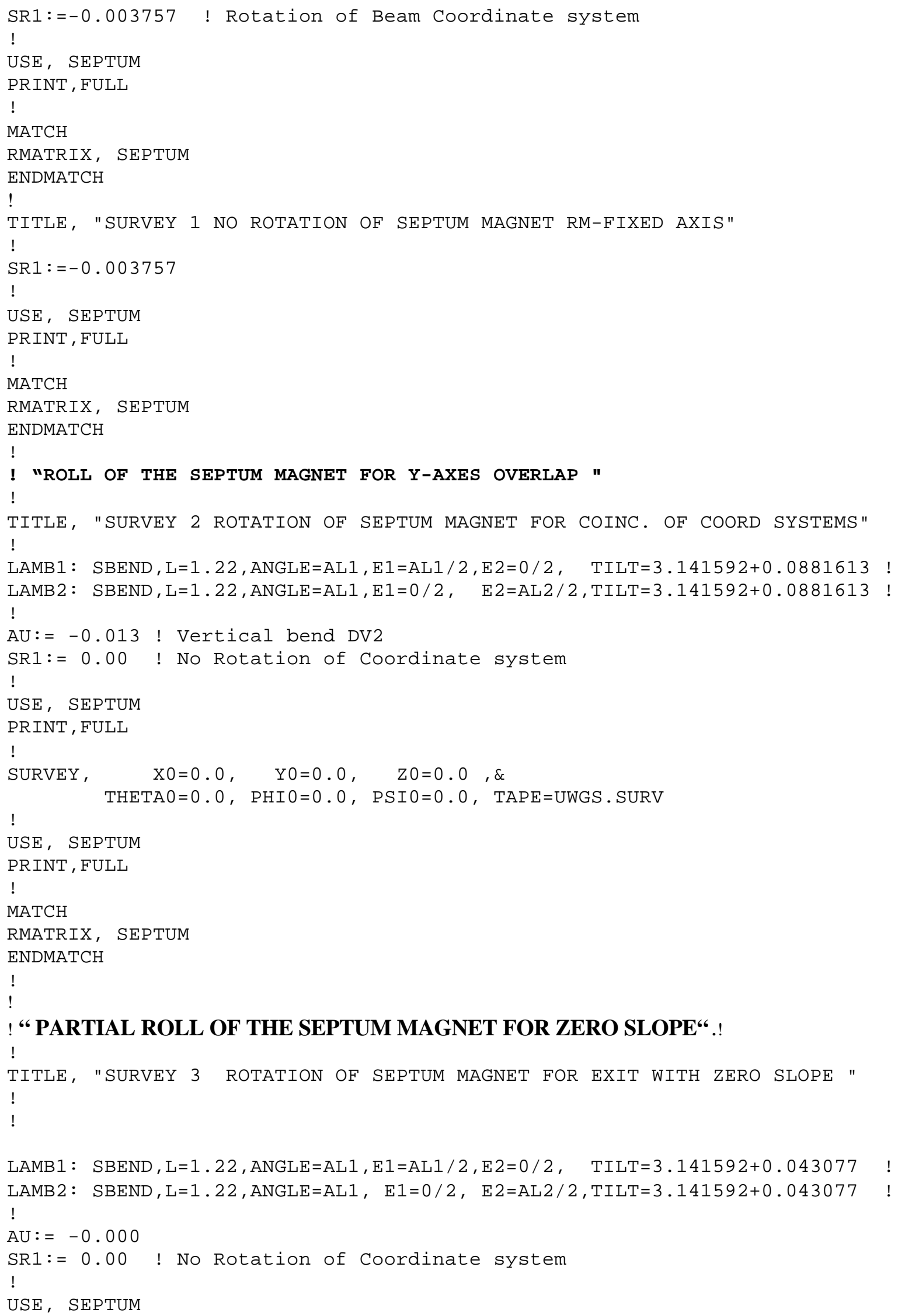




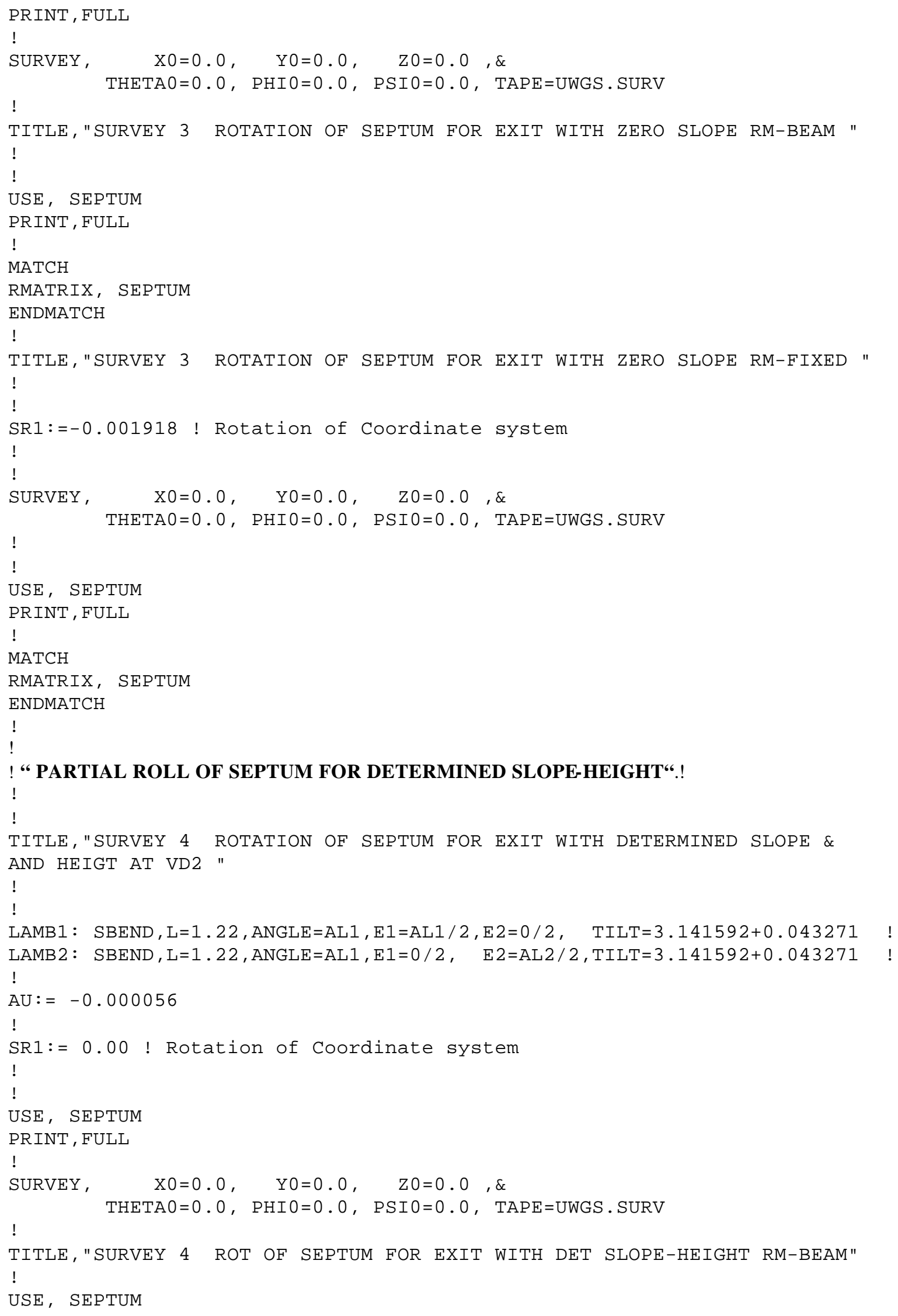




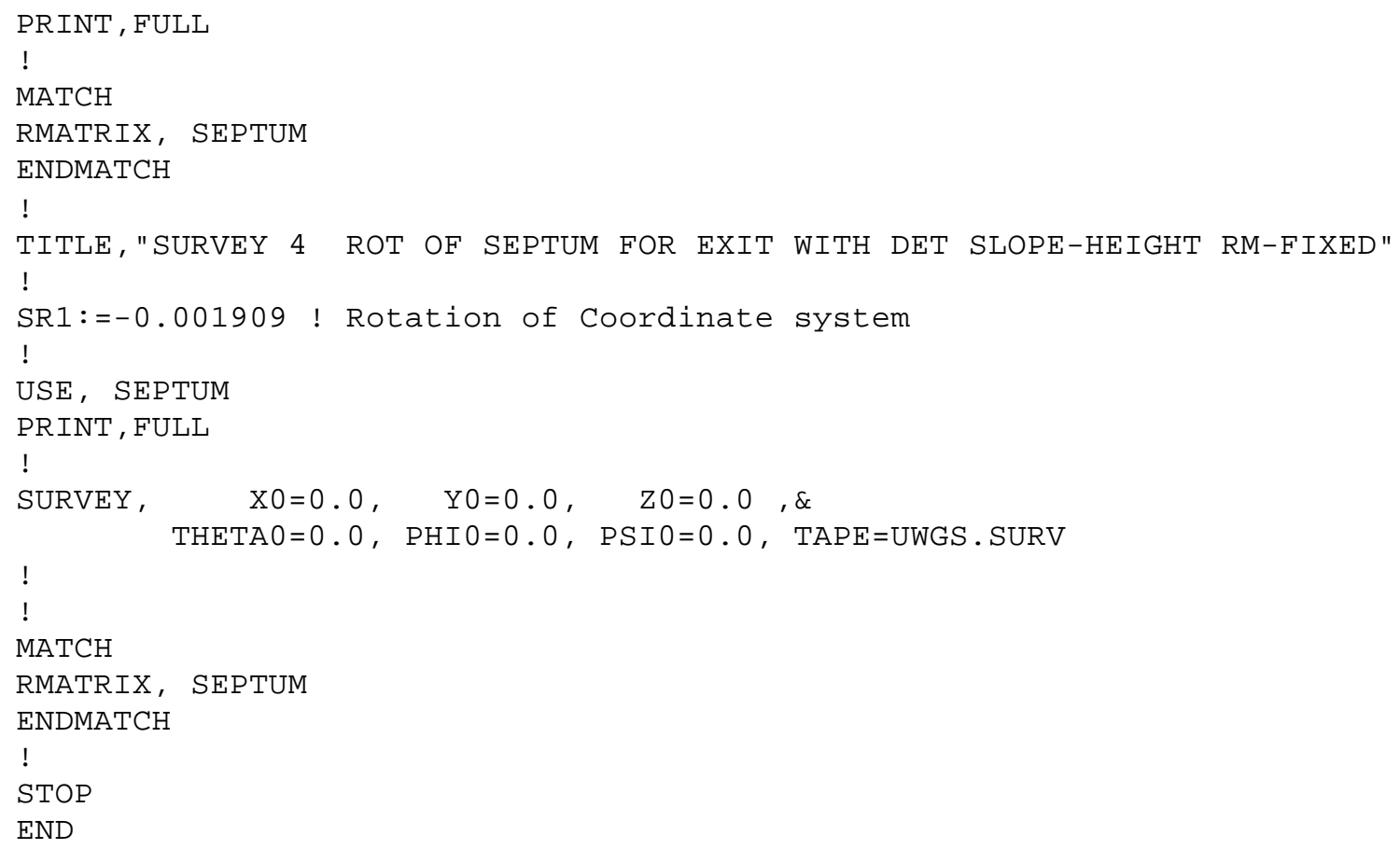




\section{APENDIX II}

“ NO ROLL OF THE SEPTUM MAGNET “

\begin{tabular}{|c|c|c|c|c|c|c|c|c|}
\hline $\begin{array}{l}\text { ELEM } \\
\text { pos. } \\
\text { no. }\end{array}$ & $\begin{array}{l}\mathrm{SEQ} \\
\text { element } \\
\text { name }\end{array}$ & $\operatorname{sum}_{[\mathrm{m}]}(\mathrm{L})$ & $\begin{array}{ccc}P & O S \\
x \\
\\
& {[\mathrm{~m}]}\end{array}$ & $\begin{array}{cccc}T & I & O & N \\
& y \\
& & {[\mathrm{~m}]}\end{array}$ & $\begin{array}{c}\mathrm{z} \\
{[\mathrm{m}]}\end{array}$ & $\begin{array}{l}\text { theta } \\
\text { [rad] }\end{array}$ & $\begin{array}{c}\text { A N G L E } \\
\text { phi } \\
{[\mathrm{rad}]}\end{array}$ & $\begin{array}{l}\mathrm{psi} \\
{[\mathrm{rad}]}\end{array}$ \\
\hline begin & SEPTUM & 0.000 & 0.0000 & 0.0000 & 0.0000 & 0.00000 & 0.00000 & 0.00000 \\
\hline 1 & SD 1 & 0.000 & 0.0000 & 0.0000 & 0.0000 & 0.00000 & 0.00000 & 0.00000 \\
\hline 2 & DVD & 0.500 & 0.0000 & -0.0033 & 0.5000 & 0.00000 & -0.01300 & 0.00000 \\
\hline 3 & $\mathrm{SD} 2$ & 13.100 & 0.0000 & -0.1671 & 13.0989 & 0.00000 & -0.01300 & 0.00000 \\
\hline 4 & LAMB 1 & 14.320 & 0.0895 & -0.1829 & 14.3144 & 0.14661 & -0.01286 & 0.00190 \\
\hline 5 & LAMB2 & 15.540 & 0.3552 & -0.1983 & 15.5039 & 0.29322 & -0.01245 & 0.00376 \\
\hline 6 & SD 3 & 16.540 & 0.6442 & -0.2108 & 16.4612 & 0.29322 & -0.01245 & 0.00376 \\
\hline 7 & DVU & 17.040 & 0.7887 & -0.2139 & 16.9398 & 0.29318 & 0.00000 & 0.00376 \\
\hline 8 & SD 3 & 18.040 & 1.0777 & -0.2139 & 17.8971 & 0.29318 & 0.00000 & 0.00376 \\
\hline 9 & SD 4 & 19.040 & 1.3667 & -0.2139 & 18.8545 & 0.29318 & 0.00000 & 0.00376 \\
\hline end & SEPTUM & 19.040 & 1.3667 & -0.2139 & 18.8545 & 0.29318 & 0.00000 & 0.00376 \\
\hline
\end{tabular}

\section{R-MATRIX AT THE EXIT OF EXTRACTION REGION "BEAM-coord"}

$\begin{array}{rrrrrr}0.910165 & 17.827209 & 0.000000 & 0.000000 & 0.000000 & -1.377181 \\ -0.018196 & 0.742294 & 0.000000 & 0.000000 & 0.000000 & -0.291928 \\ 0.000000 & 0.000000 & 0.917368 & 17.882143 & 0.000000 & 0.201489 \\ 0.000000 & 0.000000 & -0.017458 & 0.749775 & 0.000000 & -0.002641 \\ 0.290762 & 4.181985 & -0.001095 & 0.198299 & 1.000000 & -0.032250 \\ 0.000000 & 0.000000 & 0.000000 & 0.000000 & 0.000000 & 1.000000\end{array}$

R-MATRIX AT THE EXIT OF EXTRACTION REGION "FIXED-coord"

$\begin{array}{rrrrrr}0.910158 & 17.827084 & -0.003447 & -0.067183 & 0.000000 & -1.377928 \\ -0.018196 & 0.742289 & 0.000066 & -0.002817 & 0.000000 & -0.291916 \\ 0.003419 & 0.066977 & 0.917362 & 17.882017 & 0.000000 & 0.196314 \\ -0.000068 & 0.002789 & -0.017458 & 0.749769 & 0.000000 & -0.003738 \\ 0.290762 & 4.181985 & -0.001095 & 0.198299 & 1.000000 & -0.032250 \\ 0.000000 & 0.000000 & 0.000000 & 0.000000 & 0.000000 & 1.000000\end{array}$

" ROLL OF THE SEPTUM MAGNET FOR Y-AXES OVERLAP" .

\begin{tabular}{|c|c|c|c|c|c|c|c|c|}
\hline $\begin{array}{l}\text { pos. } \\
\text { no. }\end{array}$ & $\begin{array}{l}\text { ELEM } \\
\text { element } \\
\text { name }\end{array}$ & $\begin{array}{c}\operatorname{SEQ} \\
\operatorname{sum}(\mathrm{L}) \\
{[\mathrm{m}]}\end{array}$ & $\begin{array}{ccc}P & O S & I \\
& x \\
& {[m]}\end{array}$ & $\begin{array}{c}\text { I } \mathrm{T} I \mathrm{I} \\
\mathrm{y} \\
\\
\\
{[\mathrm{m}]}\end{array}$ & $\begin{array}{c}z \\
{[\mathrm{~m}]}\end{array}$ & $\begin{array}{l}\text { A N G } \\
\text { theta } \\
\text { [rad] }\end{array}$ & $\begin{array}{c}L E S \\
\quad \text { phi } \\
\\
{[\text { rad }]}\end{array}$ & $\begin{array}{l}\text { psi } \\
\text { [rad] }\end{array}$ \\
\hline \multicolumn{9}{|l|}{--} \\
\hline begin & SEPTUM & 0.000 & 0.0000 & 0.0000 & 0.0000 & 0 & 0.0 & 00 \\
\hline 1 & SD1 & 0.000 & 0.0000 & 0.0000 & 0.0000 & .00000 & 0.00000 & 00 \\
\hline 2 & DVD & 0.500 & 0.0000 & -0.0033 & 0.5000 & 0.00000 & -0.01300 & 0.00000 \\
\hline 3 & SD2 & 13.100 & 0.0000 & -0.1671 & 13.0989 & 0.00000 & -0.01300 & 0.00000 \\
\hline 4 & LAMB 1 & 14.320 & 0.0892 & -0.1750 & 14.3146 & 0.14603 & 0.00000 & 0.00095 \\
\hline
\end{tabular}




\begin{tabular}{rllllllll}
5 & LAMB2 & 15.540 & 0.3538 & -0.1670 & 15.5043 & 0.29205 & 0.01300 & 0.00000 \\
6 & SD3 & 16.540 & 0.6417 & -0.1541 & 16.4619 & 0.29205 & 0.01300 & 0.00000 \\
7 & DVU & 17.040 & 0.7856 & -0.1508 & 16.9407 & 0.29205 & 0.00000 & 0.00000 \\
8 & SD3 & 18.040 & 1.0735 & -0.1508 & 17.8983 & 0.29205 & 0.00000 & 0.00000 \\
9 & SD 4 & 19.040 & 1.3615 & -0.1508 & 18.8560 & 0.29205 & 0.00000 & 0.00000 \\
end & SEPTUM & 19.040 & 1.3615 & -0.1508 & 18.8560 & 0.29205 & 0.00000 & 0.00000 \\
\hline
\end{tabular}

\section{R-MATRIX AT THE EXIT OF EXTRACTION REGION "BEAM-coord"}

$\begin{array}{rrrrrr}0.910109 & 17.826511 & -0.000052 & -0.003702 & 0.000000 & -1.371835 \\ -0.018222 & 0.741856 & -0.000017 & -0.000210 & 0.000000 & -0.290777 \\ -0.000050 & -0.003704 & 0.917364 & 17.881815 & 0.000000 & 0.137437 \\ -0.000017 & -0.000211 & -0.017459 & 0.749756 & 0.000000 & -0.002919 \\ 0.289633 & 4.165786 & 0.000286 & 0.154452 & 1.000000 & -0.032001 \\ 0.000000 & 0.000000 & 0.000000 & 0.000000 & 0.000000 & 1.000000\end{array}$

\section{R-MATRIX AT THE EXIT OF EXTRACTION REGION "FIXED-coord"}

$\begin{array}{rrrrrr}0.910109 & 17.826511 & -0.000052 & -0.003702 & 0.000000 & -1.371835 \\ -0.018222 & 0.741856 & -0.000017 & -0.000210 & 0.000000 & -0.290777 \\ -0.000050 & -0.003704 & 0.917364 & 17.881815 & 0.000000 & 0.137437 \\ -0.000017 & -0.000211 & -0.017459 & 0.749756 & 0.000000 & -0.002919 \\ 0.289633 & 4.165786 & 0.000286 & 0.154452 & 1.000000 & -0.032001 \\ 0.000000 & 0.000000 & 0.000000 & 0.000000 & 0.000000 & 1.000000\end{array}$

"PARTIAL ROLL OF THE SEPTUM MAGNET FOR ZERO SLOPE"

\begin{tabular}{|c|c|c|c|c|c|c|c|c|}
\hline $\begin{array}{c}\text { pos. } \\
\text { no. }\end{array}$ & $\begin{array}{l}\text { ELEM } \\
\text { element } \\
\text { name }\end{array}$ & $\begin{array}{l}\text { SEQ } \\
\quad \operatorname{sum}(L) \\
{[\mathrm{m}]}\end{array}$ & $\begin{array}{cccc}P & O & S & I \\
& x & \\
& & \\
& {[m]}\end{array}$ & $\begin{array}{cccc}\mathrm{T} & \mathrm{I} O \mathrm{~N} \\
& \mathrm{Y} & \\
& {[\mathrm{m}]}\end{array}$ & $\begin{array}{l}z \\
{[\mathrm{~m}]}\end{array}$ & $\begin{array}{c}\text { A N } \\
\text { theta } \\
{[\text { rad }]}\end{array}$ & $\begin{array}{l}\text { L E S } \\
\text { phi } \\
\quad[\text { rad] }\end{array}$ & $\begin{array}{l}\text { psi } \\
\text { [rad] }\end{array}$ \\
\hline gin & SEPT & 0 & 0.000 & 0.0000 & .0 & 0.0000 & 0 . & 0.0 \\
\hline 1 & SD1 & & 0000 & 0.0000 & 0 & 00 & & \\
\hline 2 & DVD & 0.500 & 0.0000 & -0.0033 & 0.5000 & 0.0000 & -0.01300 & 0.00000 \\
\hline 3 & 3 SD 2 & .100 & 0.0000 & -0.1671 & 13.0989 & 00 & -0. & \\
\hline 4 & LAME & & 2 & -0.1 & & & -0 . & \\
\hline 5 & F LAMB & 0 & 0.3548 & -0.1830 & 15.5 & .2 & 0 . & 0 . \\
\hline 6 & 5 SD 3 & 5.540 & 0.6436 & -0.1830 & 16.4615 & 0.2929 & 0.00 & 0.00192 \\
\hline 7 & DVU & 17.040 & 0.7879 & -0.1830 & 16.9402 & 0.2929 & 0.00000 & 0.00192 \\
\hline 8 & 3 SD 3 & 3.040 & 1.0767 & -0.1830 & 17.8976 & 0.2929 & 0.00000 & 0.00192 \\
\hline 9 & SD 4 & 9.040 & 1.3654 & -0.1830 & 18.8550 & 0.2929 & & 0.00192 \\
\hline end & SEPTUM & 19.040 & 1.3654 & -0.1830 & 18.8550 & 0.2929 & 0.00000 & 0.00192 \\
\hline
\end{tabular}

R-MATRIX AT THE EXIT OF EXTRACTION REGION "BEAM-cOOrd"

$\begin{array}{rrrrrr}0.910829 & 17.838534 & -0.000025 & -0.001817 & 0.000000 & -1.376423 \\ -0.017901 & 0.747303 & -0.000008 & -0.000104 & 0.000000 & -0.291881 \\ -0.000025 & -0.001817 & 0.917367 & 17.882074 & 0.000000 & 0.170162 \\ -0.000008 & -0.000104 & -0.017458 & 0.749770 & 0.000000 & -0.002777 \\ 0.290492 & 4.178106 & -0.000419 & 0.176853 & 1.000000 & -0.032518 \\ 0.000000 & 0.000000 & 0.000000 & 0.000000 & 0.000000 & 1.00000\end{array}$




\section{R-MATRIX AT THE EXIT OF EXTRACTION REGION "FIXED-COOrd"}

$\begin{array}{rrrrrr}0.910827 & 17.838504 & -0.001785 & -0.036115 & 0.000000 & -1.376746 \\ -0.017901 & 0.747302 & 0.000025 & -0.001542 & 0.000000 & -0.291875 \\ 0.001722 & 0.032397 & 0.917365 & 17.882038 & 0.000000 & 0.167522 \\ -0.000042 & 0.001330 & -0.017458 & 0.749769 & 0.000000 & -0.003337 \\ 0.290492 & 4.178106 & -0.000419 & 0.176853 & 1.000000 & -0.032518 \\ 0.000000 & 0.000000 & 0.000000 & 0.000000 & 0.000000 & 1.000000\end{array}$

"PARTIAL ROLL OF THE SEPTUM FOR PREDETERMINED BEAM HEIGHT".

\begin{tabular}{|c|c|c|c|c|c|c|c|c|}
\hline $\begin{array}{l}\text { pos. } \\
\text { no. }\end{array}$ & $\begin{array}{l}\text { ELEM } \\
\text { element } \\
\text { name }\end{array}$ & $\begin{array}{l}\mathrm{SEQ} \\
\quad \operatorname{sum}(\mathrm{L}) \\
{[\mathrm{m}]}\end{array}$ & $\begin{array}{ccc}P & O S \\
& x \\
& & {[\mathrm{~m}]}\end{array}$ & $\begin{array}{clll}\mathrm{T} & \mathrm{I} & \mathrm{O} & \mathrm{N} \\
& \mathrm{y} & & \\
& {[\mathrm{m}]} & \end{array}$ & $\begin{array}{l}z \\
{[\mathrm{~m}]}\end{array}$ & $\begin{array}{c}\text { A N } \\
\text { theta } \\
\text { [rad] }\end{array}$ & $\begin{array}{l}\text { L E S } \\
\text { phi } \\
\\
\text { [rad] }\end{array}$ & $\begin{array}{l}\text { psi } \\
\text { [rad] }\end{array}$ \\
\hline gin & SEPT & 0 & .0000 & 0.0000 & 0.00 & 0.0000 & 0.00 & . \\
\hline 1 & SD 1 & 0 & .0000 & 0.0000 & 0 & 00 & 0.00 & 00 \\
\hline 2 & DVD & 0.500 & 0.0000 & -0.0032 & 0.5000 & 0.0000 & -0.013 & 0. \\
\hline 3 & SD2 & م & 0.0000 & -0.1671 & $13 . c$ & 0.0 & -0.01 & 0 . \\
\hline 4 & LAMB1 & & 0.0892 & -0.17 & 14. & 0.1 & -0 . & 0 . \\
\hline 5 & LAMB & & & -0 & & & & \\
\hline 6 & SD 3 & 0 & .6436 & -0.1829 & 16. & 0.2 & 0 . & 0 . \\
\hline 7 & DVU & .0 & .7879 & -0.1829 & 16.5 & 0.2929 & 0.00 & 191 \\
\hline 8 & SD 3 & .040 & .0767 & -0.1829 & 17.8976 & 0.2929 & 0.00000 & 0.00191 \\
\hline 9 & SD 4 & 0 & 1.3654 & -0.1829 & 18.8 & 0.2929 & 0.00 & 0.00191 \\
\hline end & SEPTUM & 9.040 & 1.3654 & -0.1829 & 18.8550 & 0.2929 & 0.00000 & 0.00191 \\
\hline
\end{tabular}

R-MATRIX AT THE EXIT OF EXTRACTION REGION "BEAM-COOrd"

$\begin{array}{rrrrrr}0.910829 & 17.838534 & -0.000025 & -0.001826 & 0.000000 & -1.376411 \\ -0.017901 & 0.747303 & -0.000008 & -0.000104 & 0.000000 & -0.291879 \\ -0.000025 & -0.001825 & 0.917367 & 17.882074 & 0.000000 & 0.170021 \\ -0.000008 & -0.000104 & -0.017458 & 0.749770 & 0.000000 & -0.002778 \\ 0.290490 & 4.178071 & -0.000416 & 0.176757 & 1.000000 & -0.032518 \\ 0.000000 & 0.000000 & 0.000000 & 0.000000 & 0.000000 & 1.000000\end{array}$

R-MATRIX AT THE EXIT OF EXTRACTION REGION "FIXED-coord"

$\begin{array}{rrrrrr}0.910827 & 17.838505 & -0.001777 & -0.035962 & 0.000000 & -1.376733 \\ -0.017901 & 0.747302 & 0.000025 & -0.001536 & 0.000000 & -0.291873 \\ 0.001714 & 0.032228 & 0.917365 & 17.882037 & 0.000000 & 0.167393 \\ -0.000042 & 0.001322 & -0.017458 & 0.749769 & 0.000000 & -0.003335 \\ 0.290490 & 4.178071 & -0.000416 & 0.176757 & 1.000000 & -0.032518 \\ 0.000000 & 0.000000 & 0.000000 & 0.000000 & 0.000000 & 1.000000\end{array}$

